\title{
METHODICAL ASPECTS OF THE LTO CYCLE USE FOR ENVIRONMENTAL IMPACT ASSESSMENT OF AIR OPERATIONS BASED ON THE WARSAW CHOPIN AIRPORT
}

\author{
Marta GALANT-GOŁĘBIEWSKA (D), Remigiusz JASIŃSKI (D), Monika GINTER (D), \\ Marta MACIEJEWSKA (D), Mateusz NOWAK (D), Paula KURZAWSKA (D) \\ Faculty of Civil and Transport Engineering, Poznan University of Technology, Poznan, Poland
}

Received 15 April 2019; accepted 29 July 2020

\begin{abstract}
The aviation engines homologation process takes place in LTO (Landing and Take-Off) test cycle. Mentioned procedure is good for the approval applications because the test conditions are repeatable and obtained results could be compared between different engines. The authors compared in this article the exhaust emission results obtained in LTO test cycle during selected engine homologation with values obtained in estimations. Two Allied Signal TFE731-2-2B engines with a thrust of $15.6 \mathrm{kN}$ were taken into considerations. The engines are used to propel the popular VLJ (Very Light Jet) aircraft: Dassault Falcon 100. Adopted methodology of emission estimation is very similar to the LTO, because the authors use the emission factors obtained in LTO cycle, specified for selected engines. Also, the duration of take-off, climb-out and approach LTO phases were adopted to the estimations. In the analyzed case, 16 scenarios of taxi phase were selected on the basis of the Warsaw Chopin Airport available runways. Duration of taxi phase in these cases vary between 3.1 to 11.0 minutes which is at least $58 \%$ less than in LTO test. Assuming the real taxi times change the exhaust emission results comparing to normal LTO cycle up to about $64 \%$. The proposed methodology could be used for assessing environmental impact of air operations, which can be used to create the reports with more accurate data than with typical LTO times.
\end{abstract}

Keywords: LTO cycle, exhaust gas emission, airport emission, taxiing, air quality, Warsaw airport.

\section{Introduction}

The air transport evolution forecasts are published annually. The Airbus Global Market Forecast indicates that the air traffic doubles every 15 years (Airbus, 2016). It means that problem of emissions from air transport will be more noticeable. Standard procedure to estimate aircrafts impact on immediate vicinity of the airport is LTO test (International Civil Aviation Organization [ICAO], 2011, 2008). It is a tool for the emission assessment of aircraft engines, by defining the time of individual phases and the load on the drive unit, also it is possible to ensure repeatable conditions. Currently, work is underway to extend the approval process of aircraft engines, especially to measure particulate matter, which in the current legislative form is treated marginally (Jasiński et al., 2017). There are analytical forms for estimating particulate emissions from aircraft engines (such as FOA3 - First Order Approximation), but they are not used in official approval procedures. The majority of toxic exhaust compounds are emitted at very high altitudes. Therefore, the exhaust emissions from aviation does not have a significant impact on the quality of air in the global aspect. The biggest threat associated with the operation of aircraft is exhaust emissions near the airport, which directly affects the quality of air around the airport and adjacent urban agglomerations (Jasiński, 2018, 2017; Postorino et al., 2019; Zaporozhets \& Synylo, 2016). Most of the time aircraft spend on the ground is taken by taxi operations. Taxi times also increase at higher rates than traffic demand because of congestion at airports (Khammash et al., 2017). Scientific research shows that particulate matter is the biggest problem, especially the large particles number (Jasiński, 2019, 2018). Particles of the smallest size reach the pulmonary follicles and penetrate the body that is unable to cleanse itself. The effects are cardiovascular, respiratory and cancer diseases. Children and elderly people are most exposed to the negative effects of breathing polluted air. According to WHO (World Health Organization, 2018) report, it is estimated that on average, European life is shortened by around 20\% due to various air pollutants. Research is increasingly carried out on the analysis of global exhaust emissions. Estimation

*Corresponding author. E-mail: monika.t.kardach@doctorate.put.poznan.pl 
of pollutant emissions from various transport branches is based on various mathematical models based on transport volume and emission data from homologation tests (Markowski et al., 2017; Nowak et al., 2018; Nowak \& Pielecha, 2017). In the case of aviation, it is popular to use the LTO test as a tool for estimating and predicting the exhaust emission at a given air traffic and location (Nowak et al., 2019). Such analysis is subject to a very large error due to the different behavior of pilots (Galant \& Merkisz, 2017; Galant et al., 2019) and, in particular, different infrastructure conditions at specific airports (Merkisz et al., 2017). In the LTO test, the taxiing phase has the largest share in the total emissions from all phases due to its long duration and fuel burnt (Nikoleris et al., 2011). At the same time, the discussed phase in real conditions of aircraft operation is very much dependent on the airport infrastructure and the size of the airport. Using the LTO test to estimate emissions of exhaust gases in areas adjacent to the airport in a local aspect, an airport infrastructure analysis is necessary. Due to the above, the article analyzes the impact of taxi operations at a given airport on the exhaust emission estimated according to the LTO test.

\section{Methodology}

The methodology of the research is based on Landing and Take-Off (LTO) cycle available at Airport Air Quality Manual by International Civil Aviation Organization (ICAO). The cycle consists of four phases: take-off, climb, approach and taxi. An appropriate time in mode and engine thrust setting are assigned to each stage. The time in mode is given in minutes and the thrust in percent (Figure 1). The LTO cycle was created for aircraft engine certification. Unfortunately, it is sometimes used to assess exhaust emissions within airports, although the times and thrusts are average values given in the ICAO document. In order to model real emission at Warsaw Chopin Airport, it was decided to adopt the methodology of LTO cycle to the airport's infrastructure.

Warsaw Chopin Airport (Figure 2) is the biggest airport in Poland. Passenger traffic in 2018 was 17.8 million and operations in passenger traffic in that year was 189 thousand. It has two crossing runways (marked on

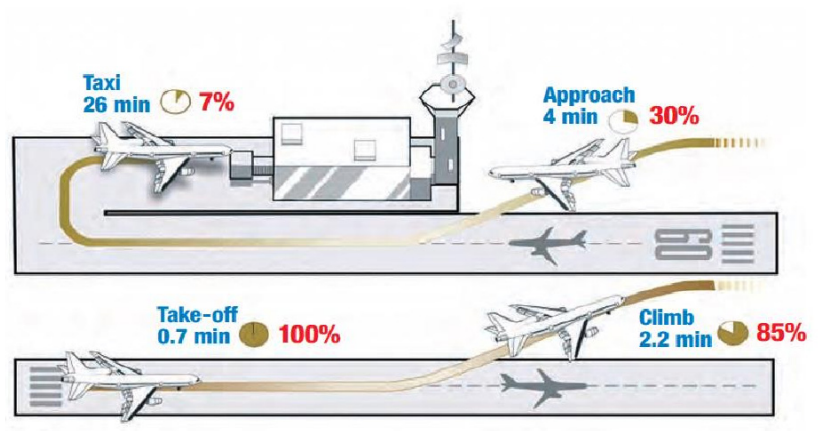

( Thrust settings

Figure 1. LTO cycle scheme (source: Prakash, 2016) the red color in Figure 2). Percentage of runway utilization in 2008 was 58.08\% (Górecka, 2012). According to AIP (Aeronautical Information Publication, 2019) to the noise emission limitation the preference system has been established: for arrivals RWY 33, RWY 11, RWY 15 and RWY 29; for departures: RWY 29, RWY 15, RWY 33, RWY 11 (Figure 2). It means that it is possible to create 16 scenarios of RWY using, characterized in different taxiing time (Table 1).

In order to calculate the emissions accurately (adjusted to the Warsaw Chopin Airport), the distance that the aircraft must cover during taxiing were measured based on the airport chart. The distances in different scenarios of taxiing were calculated. A Very Light Jet (VLJ) aircraft was selected to the analysis due to the data availability and its potential for further research (light jets' movement can be simulated in Poznan University of Technology Simulation

Table 1. Scenarios used for further analysis

\begin{tabular}{|l|c|c|c|c|}
\hline $\begin{array}{c}\text { Arrival } \\
\text { Departure }\end{array}$ & RWY33 & RWY11 & RWY15 & RWY29 \\
\hline RWY29 & A & B & C & D \\
\hline RWY15 & E & F & G & H \\
\hline RWY33 & I & J & K & L \\
\hline RWY11 & M & N & O & P \\
\hline
\end{tabular}

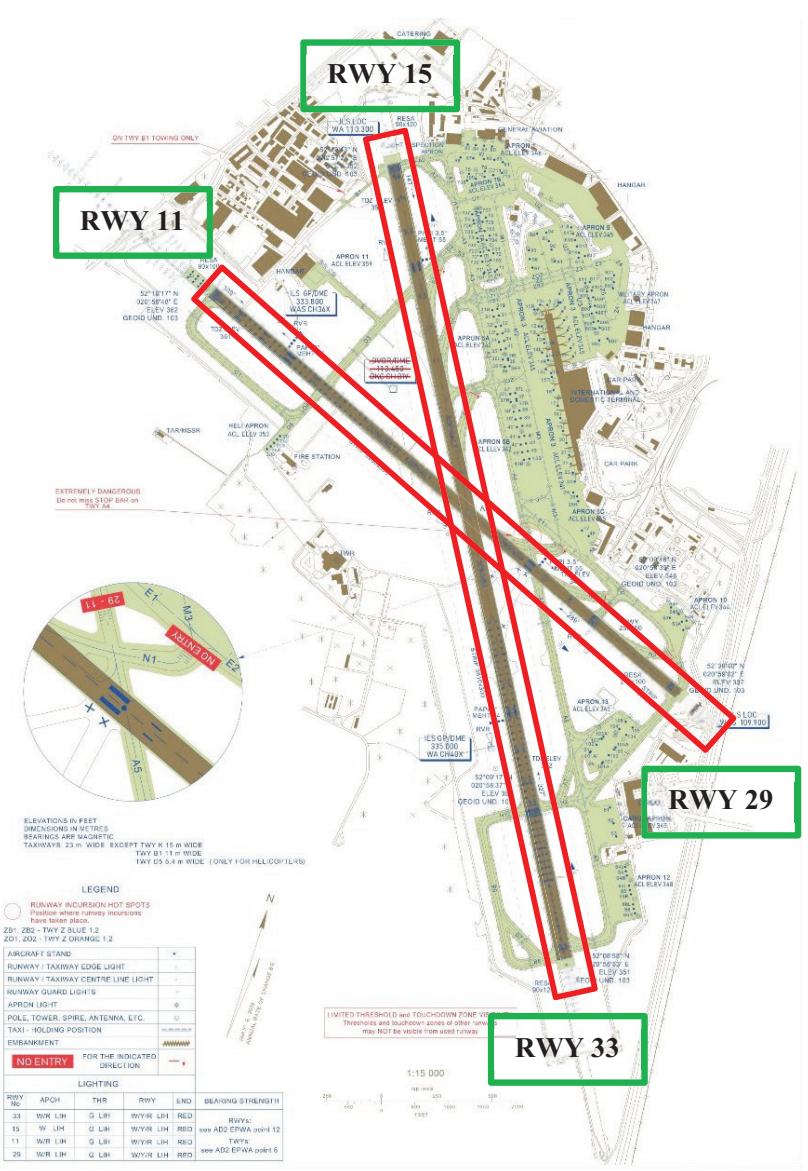

Figure 2. Warsaw Chopin Airport (Aeronautical Information Publication [AIP], 2019) 

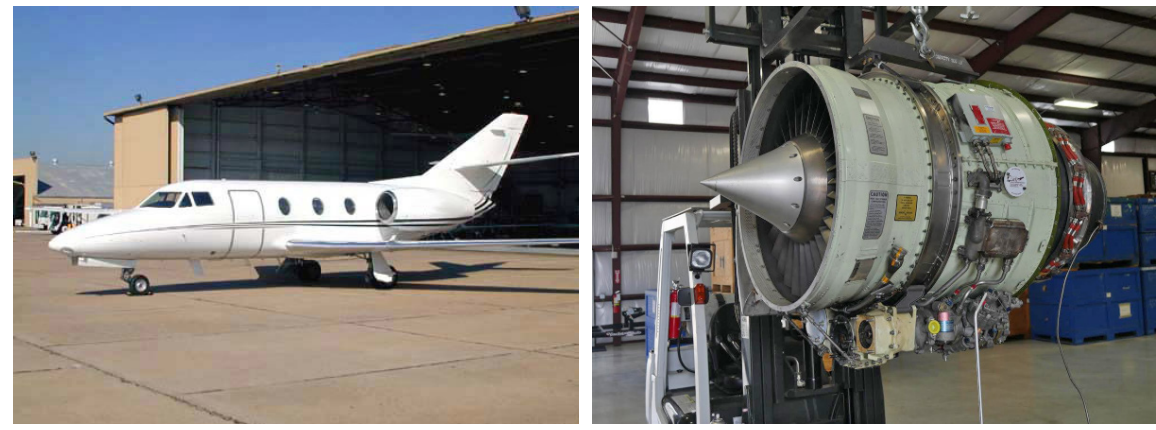

Figure 3. Dassault Falcon 100 aircraft and view of engine (Globalair, 2021; Aviation \& Marketing International, 2021)

Table 2. Dassault Falcon 100 aircraft technical specifications (Globalair, 2021)

\begin{tabular}{|l|c|c|c|c|c|c|c|}
\hline Manufacturer & Production year & engines & thrust & BEM & MTOW & V max & Range \\
\hline $\begin{array}{l}\text { Dassault } \\
\text { Aviation (FR) }\end{array}$ & $1971-1989$ & $2 \times$ TFE731-2-2B & Each engine: $15.6 \mathrm{kN}$ & $4880 \mathrm{~kg}$ & $8500 \mathrm{~kg}$ & $907 \mathrm{~km} / \mathrm{h}$ & $3560 \mathrm{~km}$ \\
\hline
\end{tabular}

Note: BEM - Basic Empty Mass; MTOW - Maximum Take-Off Weight; V max - maximum speed.

Laboratory). Engines mounted on this type of aircraft are the smallest of those included in the LTO emission database, published on the Internet website of EASA (European Aviation Safety Agency). Given the availability of data, the analysis selected the Dassault Falcon 100 aircraft (shown in Figure 3, Table 2), driven by 2 engines of Allied Signal: TFE731-2-2B (Aviation \& Marketing International, 2021), with a thrust of $15.6 \mathrm{kN}$ each (Table 2).

Based on the selected aircraft and engine, the emission indicators from the LTO test base, prepared by EASA, were used for the analysis.

Table 3. Emission indexes for TFE731-2-2B engine (EASA, 2021)

\begin{tabular}{|l|c|c|c|c|}
\hline \multirow{2}{*}{$\begin{array}{c}\text { Power } \\
\text { settings }\end{array}$} & \multirow{2}{*}{$\begin{array}{c}\text { Fuel flow } \\
{[\mathrm{kg} / \mathrm{sec}]}\end{array}$} & \multicolumn{3}{|c|}{ Emission index [g/kg fuel] } \\
\cline { 3 - 5 } & & $\mathrm{NOx}$ & $\mathrm{CO}$ & $\mathrm{HC}$ \\
\hline $\mathrm{T} / \mathrm{O}$ & 0.205 & 15.25 & 1.394 & 0.114 \\
\hline $\mathrm{C} / \mathrm{O}$ & 0.173 & 13.08 & 2.03 & 0.128 \\
\hline App & 0.067 & 5.9 & 22.38 & 4.26 \\
\hline Idle & 0.024 & 2.82 & 58.6 & 20.04 \\
\hline
\end{tabular}

Note: $\mathrm{NOx}$ - nitrogen oxides; $\mathrm{CO}$ - carbon monoxide; $\mathrm{HC}$ - hydrocarbons; T/O - Take-Off, LTO test phase; C/O - Climb out, LTO test phase; App - Approach, LTO test phase.

For the calculation of taxi operations, it was assumed that the aircraft was moving at a speed of $20 \mathrm{kts}$ $(37.04 \mathrm{~m} / \mathrm{s})$. Taxiing operations to arrival and departure are mapped. By accumulating the times of operations, it was possible to obtain the full distance (Table 4) and taxi time (Table 5) for each of the scenarios. The regulations showed in Aeronautical Information Publication (AIP) includes fact, that to general aviation is designated Apron 1. This apron is located at north part of airport, nearby to RWY 15 threshold.
Table 4. Distance in $\mathrm{km}$ of taxi operations for each scenario

\begin{tabular}{|l|c|c|c|c|}
\hline $\begin{array}{c}\text { Arrival } \\
\text { Departure }\end{array}$ & RWY33 & RWY11 & RWY15 & RWY29 \\
\hline RWY29 & 5.4 & 6 & 4.1 & 5.2 \\
\hline RWY15 & 3.2 & 3.8 & 1.9 & 3 \\
\hline RWY33 & 6.2 & 6.8 & 4.9 & 6 \\
\hline RWY11 & 5.4 & 6 & 4.1 & 5.2 \\
\hline
\end{tabular}

For the purposes of the analyses, the 16 scenarios were adopted - the longest taxiway takes $6.8 \mathrm{~km}$, the shortest $1.9 \mathrm{~km}$ and the average occurs $4.8 \mathrm{~km}$. Its caused that taxi time is from 3 to 11 minutes, not as in the LTO 26 minutes.

Table 5. Time in minutes of taxi operation for each scenario

\begin{tabular}{|l|c|c|c|c|}
\hline $\begin{array}{c}\text { Arrival } \\
\text { Departure }\end{array}$ & RWY33 & RWY11 & RWY15 & RWY29 \\
\hline RWY29 & 8.7 & 9.7 & 6.6 & 8.4 \\
\hline RWY15 & 5.2 & 6.2 & 3.1 & 4.9 \\
\hline RWY33 & 10.0 & 11.0 & 7.9 & 9.7 \\
\hline RWY11 & 8.7 & 9.7 & 6.6 & 8.4 \\
\hline
\end{tabular}

By having real taxi operations times, performed for each scenario, it was possible to calculate the actual emission of harmful compounds from the selected aircraft at the Warsaw Chopin Airport. In order to make the analysis, the following formula was used:

$$
\mathrm{EPC}_{\mathrm{pol}, \text { mode }}=(\mathrm{TIM} / 60) \cdot(\mathrm{FFR}) \cdot \mathrm{EF} \cdot \mathrm{NE} \text {, }
$$

where: $\mathrm{EPC}_{\mathrm{pol}}$, mode - Emission Per Cycle of specified pollutant in selected LTO mode [g/cycle]; TIM - Time in Mode [min/cycle]; 60 - minutes per hours [min/h]; FFR - Fuel Flow Rate $[\mathrm{kg} / \mathrm{h}]$; EF - Emission Factor $[\mathrm{g} / \mathrm{kg}]$; NE - Number of engines on the aircraft. 
After performing calculations, the following results were obtained (Table 6).

Table 6. Results of performed calculation in taxi phase (for 1 engine)

\begin{tabular}{|l|c|c|c|c|}
\hline \multirow{2}{*}{$\begin{array}{c}\text { Arrival } \\
\text { Departure }\end{array}$} & \multicolumn{4}{|c|}{ CO emission [g] } \\
\cline { 2 - 5 } & 33 & 11 & 15 & 29 \\
\hline 29 & 738.1 & 820.1 & 560.4 & 710.8 \\
\hline 15 & 437.4 & 519.4 & 259.7 & 410.1 \\
\hline 33 & 847.5 & 929.5 & 669.8 & 820.1 \\
\hline 11 & 738.1 & 820.1 & 560.4 & 710.8 \\
\hline \multirow{2}{*}{$\begin{array}{c}\text { Arrival } \\
\text { Departure }\end{array}$} & 33 & 11 & 15 & 29 \\
\cline { 2 - 5 } & & NOx emission [g] \\
\hline 29 & 35.5 & 39.5 & 27.0 & 34. \\
\hline 15 & 21.0 & 25.0 & 12.5 & 19.7 \\
\hline 33 & 40.8 & 44.7 & 32.2 & 39.5 \\
\hline 11 & 35.5 & 39.5 & 27.0 & 34.2 \\
\hline \multirow{2}{*}{$\begin{array}{c}\text { Arrival } \\
\text { Departure }\end{array}$} & 33 & 11 & 15 & 29 \\
\cline { 2 - 5 } & & HC emission [g] & \\
\hline 29 & 252.4 & 280.5 & 191.7 & 243.1 \\
\hline 15 & 149.6 & 177.6 & 88.8 & 140.2 \\
\hline 33 & 289.8 & 317.9 & 229.1 & 280.5 \\
\hline 11 & 252.4 & 280.5 & 191.6 & 243.1 \\
\hline \multirow{2}{*yyyy}{} & & & \\
\hline
\end{tabular}

\section{Research results}

Based on calculated results, the authors prepared Figure 4, which presents the mass of gaseous harmful compounds in exhaust gases obtained in LTO cycle and estimated for whole aircraft operation in the airport (approach, taxi, take-off and climb-out). For the estimations, the authors adopted different taxi scenarios at Warsaw Chopin Airport. The emission indexes in different LTO phases, specified for TFE731-2-2B engine were adopted for these estimations from EASA database (Table 3).

Analyzing the Figure 4, the mass of $\mathrm{NO}_{\mathrm{x}}$ does not vary much in analyzed scenarios. The obtained values of $\mathrm{NO}_{\mathrm{x}}$ mass for analyzed situations takes values from $1074.8 \mathrm{~g}$ to 1139.2 The differences in taxi times for these combinations of used runways are between $68 \%$ and $250 \%$ where the differences in emitted mass of $\mathrm{NO}_{\mathrm{x}}$ in whole LTO estimations are from $1 \%$ to $6 \%$ Advantageous conditions for $\mathrm{NO}_{\mathrm{x}}$ formation are high pressure and high temperature in the combustion chamber. That is the reason, why $\mathrm{NO}_{\mathrm{x}}$ emission index for analyzed engine obtained during take-off phase takes over five times greater values than during taxi phase. Also the fuel flow rate during takeoff phase is much greater, which together with greater emission index results in over 40 times greater emission intensity in the take-off phase than in the taxi phase ( $3.13 \mathrm{~g} / \mathrm{s}$ vs $0.068 \mathrm{~g} / \mathrm{s})$. Described emission dependence state, that $\mathrm{NO}_{\mathrm{x}}$ emission is mostly determined by take-off and climb-out phases despite longer duration of different taxi times. It could be concluded, that the taxi phase does not affect much the $\mathrm{NO}_{\mathrm{x}}$ emission.

Greater differences are observed in case of estimated mass of HC (Figure 4). The obtained values are from $425.3 \mathrm{~g}$ to $780.6 \mathrm{~g}$, so the differences are up to $84 \%$. The different taxi times dependent on adopted runways have real influence on the total LTO HC mass, because during taxi phase the engine operates with different thermodynamic indicators as in the take-off phase (low pressure and low temperature in the combustion chamber). That conditions are favorable for $\mathrm{HC}$ and $\mathrm{CO}$ formation. Presented results show, that adopted taxi phase duration has a crucial influence on the estimated HC mass.

Dependences described in previous paragraph explain also the big differences in CO mass for different taxi scenarios. The emission index for $\mathrm{CO}$ obtained during taxi phase is over forty times greater than during take-off phase (respectively $58.6 \mathrm{~g} / \mathrm{kg}$ fuel and $1.394 \mathrm{~g} / \mathrm{kg}$ fuel) and thus duration of taxi mode has the biggest impact on CO emission in the LTO cycle. The obtained values of CO mass in the simulated LTO test at Warsaw Chopin Airport are between 1355.9 and 2695.5 g/cycle.

In Figure 5, the authors shown the average change in $\mathrm{HC}, \mathrm{NO}_{\mathrm{x}}$ and $\mathrm{CO}$ emission between typical LTO test and estimations. Mean emission values from simulated LTO test were assumed and the values were compared to results obtained in real LTO test. The mean results

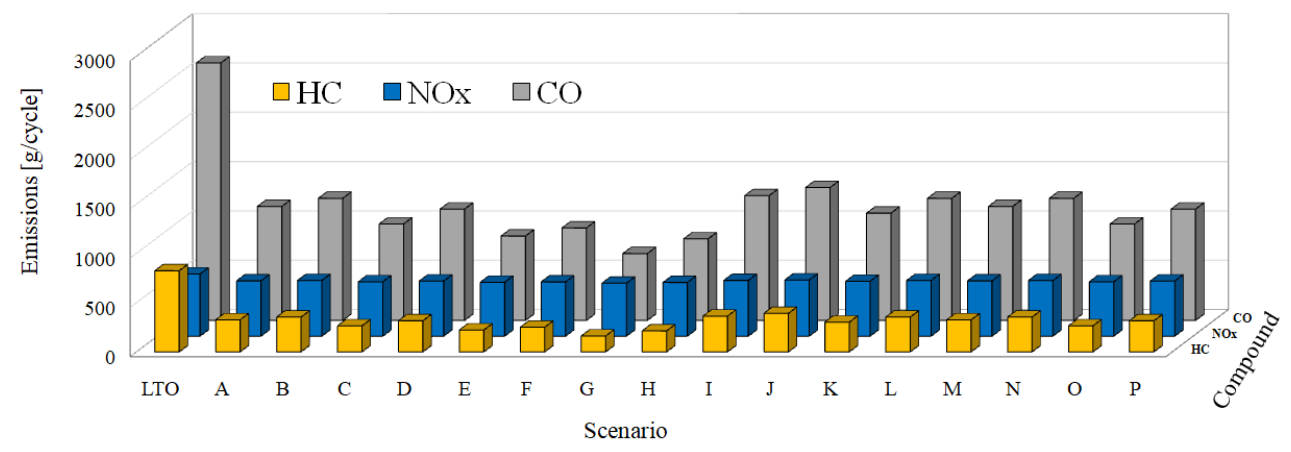

Figure 4. Exhaust emission from analysed aircraft for different combinations of take-off and landing directions compared with values adopted to the aircraft from LTO test 


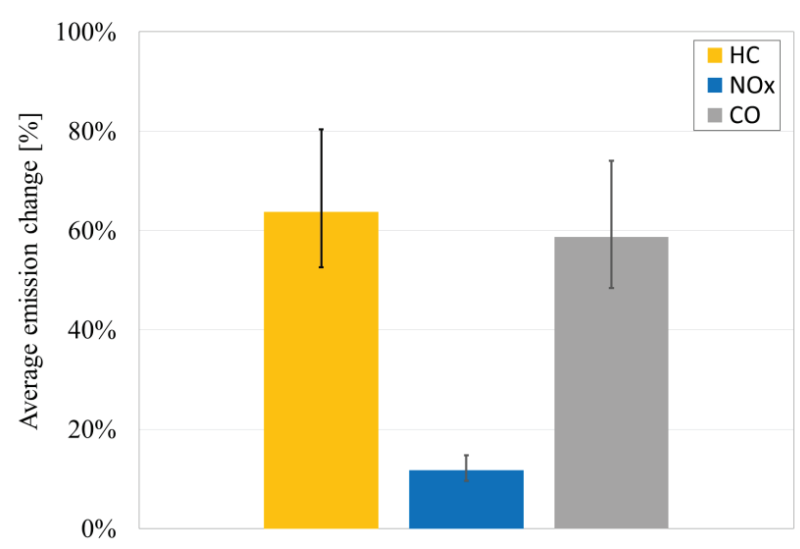

Figure 5. The relative change in emission of analysed exhaust compounds comparing average values obtained during estimations to values obtained in LTO test of TFE731-2-2B engine

correspond to the observations for single analyzed scenarios. The biggest advantage in adaptation of real taxi distances covered by aircraft operated at given airport to the LTO test is about $64 \%$ less HC emission. Similar benefit is observed in $\mathrm{CO}$ emission reduction (approx. $59 \%$ ), where the $\mathrm{NO}_{\mathrm{x}}$ emission obtained in discussed estimations is approx. $12 \%$ lower than in real LTO test of analyzed jet engine. The different emission reduction between actual LTO and test obtained for $\mathrm{HC}$ and $\mathrm{NO}_{\mathrm{x}}$ is due to the fact that the management by airports of these emissions is very different (e.g. the consequences of $\mathrm{HC}$ emissions can be mitigated by more frequent cleaning of taxiways). Assumption of emission values obtained in the LTO test during assessment of airport emission impact result in overestimation of obtained values.

\section{Conclusions}

The knowledge of actual emission data is very important in many transport aspects, for example during preparation of environmental impact report of a field of transport (air transport, road transport on specified area). Such data from reports could be further used to estimate the influence of new investments on the environmental impact of specified object. In terms of this publication it could be the impact of aircraft operation on in the area of the Warsaw Chopin Airport. Sometimes the homologation tests do not reflect the real operation conditions. As example it could be used the road vehicles homologation, where for better reflection of real operation conditions, the legislators decided to change the homologation test from NEDC (New European Driving Cycle) to WLTC (Worldwide Light vehicles Test Cycle) with additional test in real driving conditions, called RDE (Real Driving Emissions). Similar situation is observed in aviation, where homologation is processed in defined LTO cycle (Landing and Take-Off), which for most aircraft applications consists of four phases (approach, taxi, take-off and climb-out) with specified engine thrust and phase duration. Authors earlier work show, that the approach, take-off and climb-out time phases are specified correctly, but the taxi phase time during simulations was much shorter than in LTO test. This work, considering 16 scenarios of taxiing at Warsaw Chopin Airport, shows that every even the longest taxi way is shorter than in LTO cycle and these differences are between 58 to $88 \%$. This data may be of particular relevance to airport managers and aviation authorities in the countries. When preparing emission reports, real data should be taken into account, not estimation based on approval data.

To obtain the mass of individual toxic compounds emitted in exhaust gases, the authors used official emission indexes from homologation procedure of analyzed engine. The authors estimated mass of the legislative obligatory exhaust compounds: $\mathrm{CO}, \mathrm{HC}$ and $\mathrm{NO}_{x}$. During calculations, the approach, take-off and climb-out times of LTO cycle were adopted, so the only variable value was taxi time. That consideration influenced big differences in $\mathrm{CO}$ and $\mathrm{HC}$ emission (respectively -64 and $-59 \%$ ) and negligible differences in $\mathrm{NO}_{\mathrm{x}}$ emission $(-12 \%)$. The reason of different changes in obtained results are low incylinder pressure and temperature, which is favorable for $\mathrm{CO}$ and $\mathrm{HC}$ formation and less advantageous in terms of $\mathrm{NO}_{\mathrm{x}}$ formation. The differences show how big errors could be obtained during preparation of airports environmental impact reports using the official LTO emission factors. The smaller airport, the bigger error will be obtained. The most reliable results will be obtained using the real aircraft operation times specified for each airport. The authors' achievement is demonstrating the importance of choosing a taxiway for local emissions at the airport. Such analyses should be extended and recommendations issued to airport managers to limit the negative impact of air operations on air quality.

In the further works, similar measurements will be made for a larger group of airports. Such data will allow for statistical analysis of the error of inference for local emissions based only on approval tests.

\section{Funding}

This work was supported by the statutory research [contract No. 05/52/SBAD/0300] fund, Poland.

\section{References}

Aeronautical Information Publication [AIP]. (2019). The Aeronautical Information Publication (AIP) of Poland. Poland Polish Air Navigation Services Agency.

Aviation \& Marketing International [AMI]. (2021). TFE731 engines for sale. https://turbineengine.com/tfe731-engines-for-sale/ Airbus. (2016). Global Market Forecast. Airbus S.A.S. France.

EASA. (2021). ICAO Aircraft Engine Emissions Databank. https:// www.easa.europa.eu/icao-aircraft-engine-emissions-databank

Galant, M., \& Merkisz, J. (2017). Analysis of the possibilities of using EEG in assessing pilots' psychophysical condition. Scientific 
Journal of Silesian University of Technology - Series Transport, 95, 39-46. https://doi.org/10.20858/sjsutst.2017.95.4

Galant, M., Nowak, M., Kardach, M., Maciejewska, M., \& Legowik, A. (2019). Using the simulation technique to improve efficiency in general aviation. In AIP Conference Proceedings, 2078(1), 020097. https://doi.org/10.1063/1.5092100

Górecka, A. (2012). Airport throughput - the case of Frederic Chopin International Airport in Warsaw [Conference presentation]. Carpathian Logistics Conference, Jesenik, Czech Republic, EU.

Globalair. (2021). Falcon 100. https://www.globalair.com/aircraft-for-sale/Specifications? specid $=201$

International Civil Aviation Organization [ICAO]. (2011). Airport Air Quality Manual. Doc. 9889. ICAO.

International Civil Aviation Organization [ICAO]. (2008). Annex 16: Environmental protection, Vol. I: Aircraft noise (4th ed.). ICAO.

Jasiński, R. (2019). Particle emission parameter analysis from multirole fighter aircraft engine. In 2nd International Conference on the Sustainable Energy and Environmental Development, IOP Conference Series, Vol. 214, 012011, 1-7. Kraków, Poland. https://doi.org/10.1088/1755-1315/214/1/012011

Jasiński, R. (2018). Mass and number analysis of particles emitted during aircraft landing. In E3S Web of Conferences, Vol. 44, 00057. https://doi.org/10.1051/e3sconf/20184400057

Jasiński, R. (2017). Number and mass analysis of particles emitted by aircraft engine. In MATEC Web Conferences, Vol. 118, 00023. https://doi.org/10.1051/matecconf/201711800023

Jasiński, R., Markowski, J., \& Pielecha, J. (2017). Probe positioning for the exhaust emissions measurements. Procedia Engineering, 192, 381-386. https://doi.org/10.1016/j.proeng.2017.06.066

Khammash, L., Mantecchini, L., \& Reis, V. (2017, June). Microsimulation of airport taxiing procedures to improve operation sustainability: Application of semi-robotic towing tractor. In 2017 5th IEEE International Conference on Models and Technologies for Intelligent Transportation Systems (MT-ITS) (pp. 616-621). https://doi.org/10.1109/MTITS.2017.8005587

Markowski, J., Pielecha, J., \& Jasinski R. (2017). Model to assess the exhaust emissions from the engine of a small aircraft during flight. Procedia Engineering, 192, 557-562. https://doi.org/10.1016/j.proeng.2017.06.096
Merkisz, J., Galant, M., \& Bieda, M. (2017). Analysis of operating instrument landing system accuracy under simulated conditions. Journal of Silesian University of Technology - Series Transport, 94, 163-173. https://doi.org/10.20858/sjsutst.2017.94.15

Nikoleris, T., Gupta, G., \& Kistler, M. (2011). Detailed estimation of fuel consumption and emissions during aircraft taxi operations at Dallas/Fort Worth international airport. Transportation Research Part D: Transport and Environment, 16, 302-308. https://doi.org/10.1016/j.trd.2011.01.007

Nowak, M., Andrzejewski, M., Galant, M., \& Rymaniak, Ł. (2019). Simulation assessment of the selected combination of road and rail infrastructure in the aspect of choosing the route of road transport means. In AIP Conference Proceedings, 2078, 020055. https://doi.org/10.1063/1.5092058

Nowak, M., Jasiński, R., \& Galant, M. (2018). Implementation of the LTO cycle in flight conditions using FNPT II MCC simulator. Material Science and Engineering, 421(4), 042060, 1-9. https://doi.org/10.1088/1757-899X/421/4/042060

Nowak, M., \& Pielecha, J. (2017). Comparison of exhaust emission on the basis of Real Driving Emissions measurements and simulations. In MATEC Web of Conferences, Vol. 118, 00026, 1-8. https://doi.org/10.1051/matecconf/201711800026

Prakash, A. (2016, 25-27 July). Prediction of NOx Emissions for an RQL aero-engine combustor using a stirred reactor modelling approach [Conference presentation]. 52nd AIAA/SAE/ ASEE Joint Propulsion Conference. Salt Lake City, United States.

Postorino, M. N., Mantecchini, L., \& Paganelli, F. (2019). Improving taxi-out operations at city airports to reduce $\mathrm{CO} 2$ emissions. Transport Policy, 80, 167-176. https://doi.org/10.1016/j.tranpol.2018.09.002

Warshaw Chopin Airport. (2021). https://www.lotnisko-chopina.pl World Health Organization. (2018). Ambient (outdoor) ait pollution. WHO. https://www.who.int/news-room/fact-sheets/ detail/ambient-(outdoor)-air-quality-and-health

Zaporozhets, O., \& Synylo, K. (2016, 29 May-1 June). Improvements on aircraft engine emission and emission inventory assessment inside the airport area. Energy, 140(Part 2), 13501357. https://doi.org/10.1016/j.energy.2017.07.178 